\title{
Molecular cloning and characterization of NAC genes from four foxtail millet genotypes
}

\author{
Sintho Wahyuning Ardie ${ }^{a^{*}}$, Nurul Khumaida ${ }^{a}$, Tetsuo Takano ${ }^{b}$, Nike Karjunitac ${ }^{c}$ Muhammad Habib \\ Widyawan ${ }^{c}$ \\ ${ }^{a}$ Department of Agronomy and Horticulture, Faculty of Agriculture, Bogor Agricultural University (IPB), Jl. Meranti, IPB Darmaga Campus, \\ Bogor, 16680, West Java, Indonesia \\ ${ }^{b}$ Laboratory of Environmental Stress Tolerance Mechanisms, The University of Tokyo, 1-1-1 Midori-cho, Nishitokyo-shi, 188-0002, Tokyo, \\ Japan \\ 'Graduate School of Plant Breeding and Biotechnology, Bogor Agricultural University (IPB), Jl. Meranti, IPB Darmaga Campus, Bogor, 16680, \\ West Java, Indonesia
}

Received 30th November 2018 / Accepted 5th March 2019

\begin{abstract}
Transcription factor gene family of NAC ( $\underline{N A M}$, $\underline{A} T A F, \underline{C U C})$ is tightly involved in plant development and in the response to stresses. In this study, we reported the isolation and the characterization of $N A C$ gene homolog from four foxtail millet genotypes. Band with approximately 1300 bp size was successfully amplified from the genomic DNA of four foxtail millet genotypes (ICERI-4, ICERI-5, ICERI-6 and ICERI-10) using gene specific primer. The fragment was designated as SiNACO65 after showing high similarity with $N A C$ gene homologs in the GenBank. Sequence analysis results showed that the SiNAC065 genes isolated from the four genotypes were $1265 \mathrm{bp}$ in length with one intron and two exons. The two exons encode 325 amino acids with the conserved domain located between amino acid 19-325. The SiNAC065 protein identified in this study have 8 conserved motives in the conserved region which categorized them as SNAC (stress responsive NACs) orthologs that are involved in the abiotic stress responses. Different features of SiNAC065 isolated from the tolerant- and the sensitivegenotypes should provide information of the gene's role in salinity tolerance mechanism of foxtail millet.
\end{abstract}

Keywords: abiotic stress, gene cloning, Setaria italica, stress-responsive NAC, transcription factor

\section{INTRODUCTION}

Foxtail millet (Setaria italica L. Beauv) is carbohydrate producing crop with high nutritional value (Amadou et al., 2013). This crop ranks second in total millet production globally (Yang et al., 2012) and became an essential food crop particularly in areas with drought and saline conditions due to its tolerance to those conditions (Kafi et al., 2009; Karyudi and Fletcher, 2003; Panaud 2006). Several studies have been conducted to reveal the tolerance mechanism of foxtail millet to abiotic stresses, particularly to drought (Lata et al., 2010) and salinity (Islam et al., 2011) stresses.

Extensive studies in plant abiotic response showed that the genes involved in abiotic stress tolerance mechanisms were evolutionary conserved among plant species (Akpinar et al., 2012). Generally, stress related genes are classified into down-stream genes (functional genes) and up-stream genes (regulatory genes). Functional genes encode enzymes and metabolic proteins which directly function to protect cells from

*Author for correspondence: Sintho Wahyuning Ardie, Department of Agronomy and Horticulture, Faculty of Agriculture, Bogor Agricultural University (IPB), Jl. Meranti, IPB Darmaga Campus, Bogor, 16680, West Java, Indonesia. Email - sintho_wa@apps.ipb.ac.id 
stress, such as detoxification enzymes, ion transporters, late embryogenesis abundant (LEA) proteins, and heat shock proteins (HSP). Regulatory genes encode various regulatory proteins which regulate the signal transduction and gene expression in response to the stress, such as protein kinases and transcription factors (TFs) (Hirayama and Shinozaki, 2010; Akpinar et al., 2012). The NAM, ATAF1,2 and CUC2 (NAC) proteins constitute a major plant specific transcription factor (TF) family which have been shown to play wide-range of roles in various developmental programs as well as in abiotic and biotic stress responses (Olsen et al., 2005; Nakashima et al., 2012; Puranik et al., 2012). Several studies reported that the expressions NAC TF members were upregulated by salinity stress in many plants, including cereals such as foxtail millet (Puranik et al., 2013), wheat (Huang et al., 2015), rice (Hong et al., 2016), and pearl millet (Shinde et al., 2019). These studies indicated the pivotal role of NAC TF in salinity stress responses. In this study, we reported the isolation of NAC-containing domain genes from four foxtail millet genotypes. Ardie et al. (2015) has reported the salinity tolerance variation between the four foxtail millet genotypes, hence characterization of NAC TF from these genotypes would provide useful information in the breeding strategy of foxtail millet.

\section{MATERIALS AND METHODS}

\section{NAC gene homolog isolation from genomic}

$\boldsymbol{D N A}$. Four foxtail millet genotypes from Indonesian Cereal Research Institute (ICERI), namely ICERI-4, ICERI-5, ICERI-6 and ICERI10 , were used in this study due to their contrasting tolerance to salinity. ICERI-5 and ICERI-6 genotypes were reported to have better tolerance to salinity compared to ICERI-4 and ICERI-10 (Ardie et al., 2015; Lapuimakuni et al., 2018). Genomic DNA was isolated from leaves of 10 days-old foxtail millet seedlings using CTAB method (Murray and Thompson 1980). Each PCR reaction mixture of $30 \mu \mathrm{L}$ consisted of $5 \mu \mathrm{L}$ (12 ng $/ \mu \mathrm{L})$ genomic DNA, $15 \mu \mathrm{L}$ GoTaq ${ }^{\circledR}$ Green Master Mix (Promega, USA), 50 pmol of each forward (5'-ATGGGAGAAGCAGAAGCATC AGC-3') and reverse primer (5'-CTAGAACAT'T

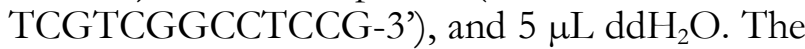
PCR cycle consisted of initial denaturing at $94^{\circ} \mathrm{C}$ for $2 \mathrm{~min}$, followed by 35 cycles at $94^{\circ} \mathrm{C}$ for $30 \mathrm{~s}$, $58^{\circ} \mathrm{C}$ annealing for $60 \mathrm{~s}$, and extension at $72^{\circ} \mathrm{C}$ for $30 \mathrm{~s}$. The final extension step was done at $72^{\circ} \mathrm{C}$ for $7 \mathrm{~min}$, then the PCR products were stored at $4^{\circ} \mathrm{C}$. PCR product was gel-purified using FastGene ${ }^{\mathrm{TM}} \mathrm{Gel} / \mathrm{PCR}$ Extraction Kit (Nippon Genetics Europe GmbH, Germany) following the manufacturer instruction and directly sequenced to Eurofin (https://eurofinsgenomics.jp/). BLASTn algorithm (http://blast.ncbi.nlm) analysis was performed to ensure the homology of the fragment with the NAC genes stored in the GenBank. Sequenced fragments were then inserted into T-vector pMD20 (TaKaRa, Japan) with the ligation reaction of $\pm 80 \mathrm{ng} / \mu \mathrm{L}$ PCR product, $1 \mu \mathrm{L}$ plasmid pMD20 $(50 \mathrm{ng} / \mu \mathrm{L})$, and 1x volume of DNA Ligation Kit Mighty Mix (TaKaRa, Japan) at $16^{\circ} \mathrm{C}$ for 45 mins. Ligation products were transformed into $E$. coli strain $\mathrm{DH} 5 \propto$, purified using FastGene $\mathrm{T}^{\mathrm{TM}}$ Plasmid MiniKit (Nippon Genetics Europe $\mathrm{GmbH}$, Germany), and sequenced to Macrogen (http://www.macrogen-japan.co.jp/).

\section{Sequence analysis of NAC gene homolog} from foxtail millet. The $N A C$ nucleotide sequences obtained were aligned and translated into amino acid sequence using Geneious software version 8.1.6 (Biomatters Ltd). Amino acid sequences were aligned using web-based program ClustalW2 (Larkin et al., 2007). Phylogenetic tree was developed by MEGA7 software (Kumar et al., 2016) using NeighborJoining method at 1000 replication bootstrap. Conserved domain analysis was conducted using BLAST on Plant Transcription Factor Database v. 4.0 (http://planttfdb.cbi.pku.edu.cn/blast. php). Visualization on conserved domain was done using WebLogo program (Crooks et al., 2004). 


\section{RESULTS AND DISCUSSION}

Fragment with the targeted size (1265 bp) was amplified by using gene specific primer (Figure 1). The gene specific primer was deduced from SiNAC065 sequence deposited in the plant genome database Phytozome (https:/phytozome. jigidoe.gov $/ \mathrm{pz} /$ portal.html). Sequence alignment analysis between the four amplified fragments with the reference sequence in Phytozome database (Phytozome identifier: Si012319m) showed that the fragments shared $99 \%$ identity with the reference sequence, thus the fragments isolated in this study were designated as SiNAC065 followed by the foxtail millet genotype name. The fragments were deposited in the GenBank as SiNAC065_ICERI4 (Accession no. KY404102), SiNAC065_ICERI5 (Accession no. KY404103), SiNAC065_ICERI6 (Accession no. KY404104), and SiNAC065_ICERI10 (Accession no. KY404105). The SiNAC065 genes isolated have one intron and two exons. The first exon spans between base 1-196, the second exon spans between base 487-1265, while the intron spans between base 197-486. The two exons encode 325 amino acids that showed high homology to similar sequences from other species in GenBank, such as Oryza brachyantha, Zea mays, Sorghum bicolor, Panicum virgatum, Brachypodium distachyon, Selaginella moellendorffii, Bambusa emeiensis, Hordeum vulgare, Aegilops tauschii, and Triticum aestivum (Figure 2).

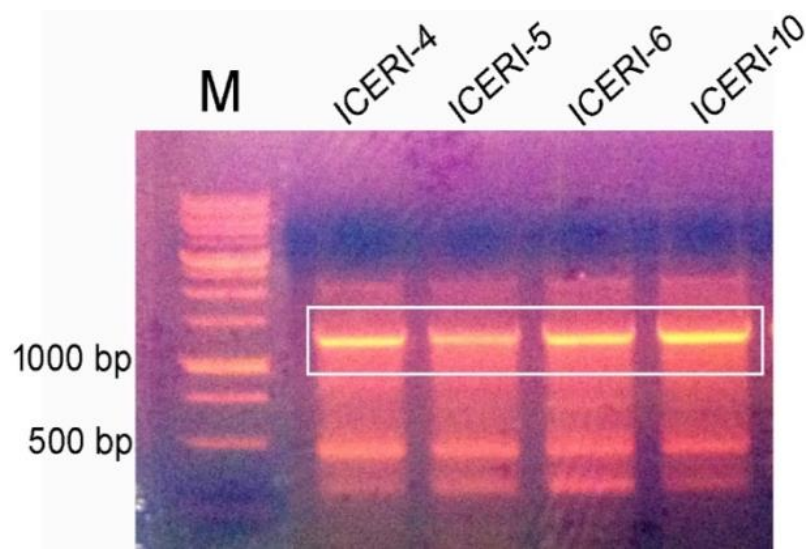

Figure 1. Amplified SiNAC065 fragment from four foxtail millet genotypes. Bands with targeted gene size (approximately $1300 \mathrm{bp}$ ) that are shown in white box were purified for further analyses.

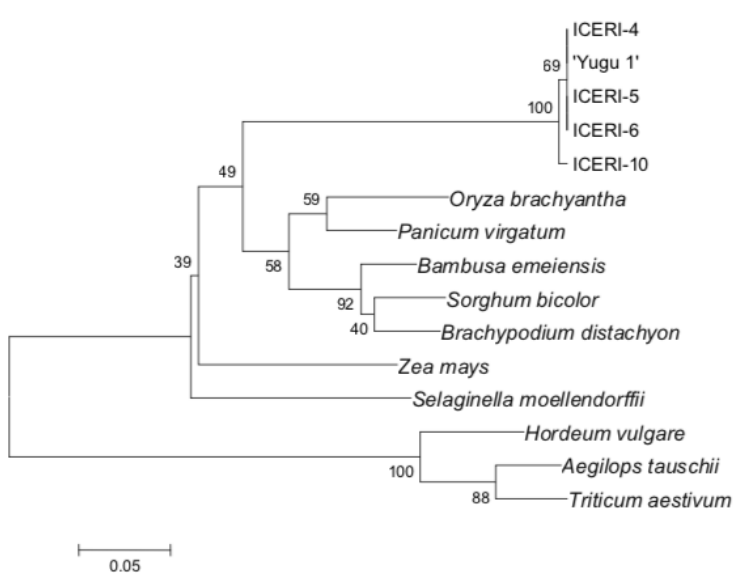

Figure 2. Unrooted minimum-evolution tree of NAC-domain containing proteins. The translated sequences of known NAC-domain containing genes were aligned by the ClustalW program and the tree was constructed using the MEGA 7 program (Kumar et al., 2016). Scale bar indicates 0.05 substitutions per site. 'Yugu 1' genotype of $S$. italica (XM_004971405.1), Oryza brachyantha (XM_006645364.1), Zea mays (JN673545.1), Sorghum bicolor (XM_002463358.1), Panicum virgatum (XM_008657306.1), Brachypodium distachyon (XM_003559734.3), Selaginella moellendorffii (XM_002987191.1), Bambusa emeiensis (HM626401.1), Hordeum vulgare (KT779954.1), Aegilops tauschii (DQ869677.1), Triticum aestivum (HQ630372.1).

Multiple sequence alignment analysis of the deduced amino acid sequences of SiNAC065 fragments isolated from the four foxtail millet genotypes and the deduced amino acid sequence of SiNAC065 from S. italica inbred 'Yugu1' reported by Bennetzen et al. (2012) deposited in NCBI GenBank database and PHYTOZOME v8.0 database (www.phytozome.net/) revealed the presence of conserved domains located in the N-terminal region (Figure 3). Domain identification analyses conducted by Puranik et al. (2013) showed that the $\mathrm{N}$-terminal region of SiNAC065 share the general structure of NAC proteins. In general, the $\mathrm{N}$-terminal NAC-domain $(\sim 150$ aa) can be divided into five sub-domains, A-E, which each possess particular function (Nakashima et al., 2012; Puranik et al., 2012). The DNA binding ability is reported to be possessed by the highly conserved positively charged $\mathrm{C}$ and D sub-domains, whereas the A sub-domain may be involved in the functional dimer formation, 
and the $\mathrm{B}$ and $\mathrm{E}$ sub-domains may be responsible for the functional diversity of NAC genes (Jensen et al., 2010; Chen et al., 2011; Puranik et al., 2012). The SiNAC065 proteins isolated in this study also have the well conserved N-terminal NACdomain. Based on the conserved motif determination of NAC TF family member in foxtail millet by Puranik et al. (2013), the Nterminal NAC-domain of SiNAC065 can be divided into 8 conserved motifs (Table 1). Two putative Nuclear Localization Signal (NLS) domains were found within the NAC domain in SiNAC65 protein, which is previously reported by Puranik et al. 2011 (Figure 2). The presence of NLS domains suggest that the SiNAC65 protein was directed into the nucleus. NLS is a short peptide motif that able to mediate the import of proteins into nuclear by binding to their receptors (Kosugi et al., 2009; Sakuma et al. 2006). It is no surprise if NLS domains are present in SiNAC65 proteins since this protein has a DNA binding ability as a transcription factor. Meanwhile, the Cterminal region of NAC TF is greatly varied among the family member and it serves as a potential transcriptional activation regions (TARs) which has either activator or repressor function and some of them possess protein binding activity (Olsen et al., 2005; Puranik et al., 2012).

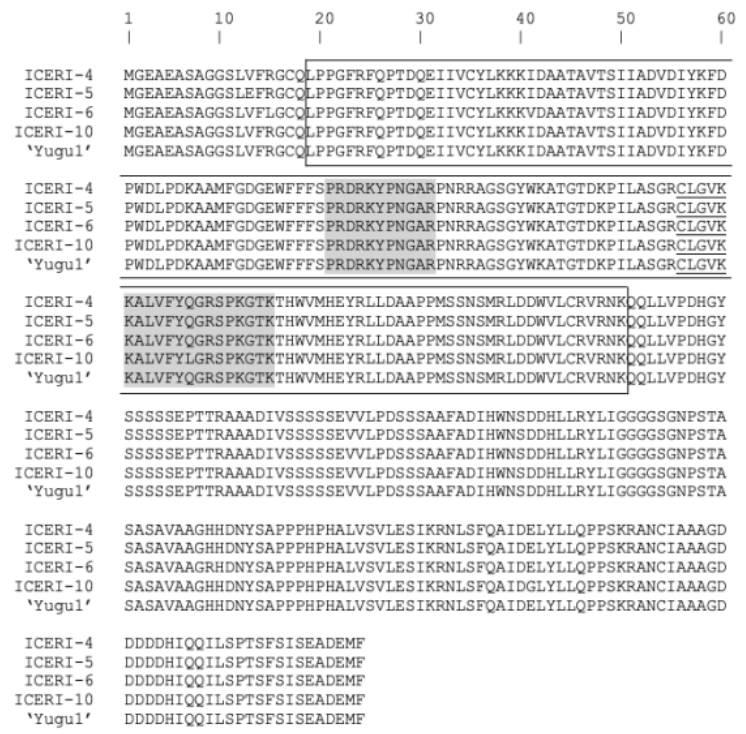

Figure 3. Identification of conserved domain found in SiNAC65 proteins. The NAC domain located in the $\mathrm{N}$-terminal was boxed and the shaded amino acid sequences was predicted as Nuclear Localization Signal.
Phylogenetic analyses and gene functional studies have clearly classified the stress-responsive NAC proteins into one group, the stress-responsive NAC (SNAC) group (Fang et al., 2008; You et al., 2015). Experimental evidences are available for some members of the SNAC group that demonstrated their functions in abiotic stress responses. For example, over-expression of SNAC1 from rice improved drought and salt tolerance in rice (Hu et al., 2006), cotton (Liu et al., 2014), and ramie (An et al., 2015), while the overexpression of $S N A C 2$ increased salt and cold tolerance in transgenic rice ( $\mathrm{Hu}$ et al., 2008) and the over-expression of ATAF1 from Arabidopsis also enhanced drought tolerance in transgenic Arabidopsis (Wu et al., 2009). Puranik et al. (2013) reported the identification of 147 putative NAC domain-encoding genes from foxtail millet and distributed them into 11 distinct sub-families. Phylogeny-based function prediction in that study indicated that the member of sub-family VII probably involved in similar regulatory roles as the SNAC orthologous in other species. SiNAC065 is one member of the 18 members of sub-family VII which was up-regulated in the early stress of drought and salinity, indicating the role of this gene in drought and salinity stress responses.

A study utilized foxtail millet cultivars with different tolerance to salinity, cv. Prasad (salttolerant) and cv. Lepakshi (salt-sensitive), showed that the salt-tolerant cultivar had better saltinduced-oxidative tolerance due to increased total superoxide dismutase (SOD) and ascorbate peroxidase (APX) activity, whereas both enzyme activities decreased in the salt-sensitive cultivar (Sreenivasulu et al., 2001). It is long-known that the increased of SOD and CAT activities correlates with lower oxidative stress induced by various abiotic stress (Dhindsa et al., 1981). The overexpression of JUB1, one of NAC TFs, dampened intracellular $\mathrm{H}_{2} \mathrm{O}_{2}$ levels and enhances tolerance to various abiotic stresses (Wu et al., 2012). Those studies indicate the possible role of NAC TFs in improving tolerance to salt stress by escalating antioxidant components in the tolerant genotypes. Whether or not SiNAC065 is involved in antioxidant component modulation still need to be further elaborated. 
Table 1. Conserved motifs identified in SiNAC065 protein.

\begin{tabular}{|c|c|c|c|}
\hline Motif No. & Amino acid sequence composition of motif & $\begin{array}{l}\text { Amino acid } \\
\text { span }\end{array}$ & $\begin{array}{c}\text { NAC sub- } \\
\text { domain }\end{array}$ \\
\hline 1 & W[YF]FF[SC]P[RK]DRKYP[TN]GSR[TP]NRAT & $76-96$ & $\mathrm{C}$ \\
\hline 2 & LPPGFRFHPTDEEL[VI]x[HYF] & $19-32$ & A \\
\hline 3 & $\mathrm{P}[\mathrm{KR}] \mathrm{Gx}[\mathrm{KR}] \mathrm{T}[\mathrm{GD}] \mathrm{W}-[\mathrm{VI}] \mathrm{MHEYRL}$ & $130-145$ & $\mathrm{D}$ \\
\hline 4 & IA[ED]VD[LI][YN][KR]C[ED]PW[DE]LP[ED]KAKIG & $50-68$ & B \\
\hline 5 & [VI]xxGGRL[VI]GM[KR]KTLVFYRGRA & $118-130$ & $\mathrm{D}$ \\
\hline 6 & $\mathrm{xx}[\mathrm{DE}][\mathrm{DE}] \mathrm{WV}[\mathrm{LV}] \mathrm{C}[\mathrm{RK}][\mathrm{VI}][\mathrm{FY}] \mathrm{K}[\mathrm{KS}] \mathrm{PR}$ & $160-171$ & $\mathrm{E}$ \\
\hline 7 & [SA]G[YF]WKATGKD[-KR] & $98-107$ & $\mathrm{C}$ \\
\hline 8 & YL[RK]RK[VA]Agx-[PR][LI]PLD[VI] & $36-41$ & - \\
\hline
\end{tabular}

The amino acid sequences were aligned with the reference sequence (Phytozome identifier: Si012319m) and conserved motifs were identified according to Puranik et al. (2013).

Characterization of genes associated with abiotic stress would be useful to develop efficient breeding strategy for tolerant variety, such as through genetic engineering (Turan et al., 2012) and molecular marker assisted breeding (Ashraf and Foolad, 2013). Previous studies reported transgenic plants overexpressing NAC gene exhibited enhanced tolerance to salinity stress (Huang et al., 2015; Hong et al., 2016; Shinde et al., 2019). Study conducted by Widyawan et al. (2018) utilized single nucleotide polymorphism (SNP) at the $558^{\text {th }}$ base of SiDREB2 gene, a TF gene which tightly associated with abiotic stress responses, to develop SNAP marker related to drought stress in foxtail millet. Similar approaches can be performed utilizing SiNAC065 gene. As a conclusion, this study has successfully isolated SiNAC065 genes from foxtail millet genotypes which differ in their salinity tolerance. Different features of SiNACO65 isolated from the tolerantand the sensitive-genotypes should provide information of the gene's role in salinity tolerance mechanism of foxtail millet.

\section{ACKNOWLEDGEMENT}

This work was supported by the Directorate General of Higher Education, Ministry of Research, Technology and Education, Republic of Indonesia

\section{REFERENCES}

Akpinar, B. A., Avsar, B., Lucas, S. J., \& Budak, H. 2012. Plant abiotic stress signalling. Plant Signalling and Behaviour 7(11): 1450-1455.

Amadou, I., Gounga, M. E., \& Le, G. W. 2013. Millets: Nutritional composition, some health benefits and processing - A Review. Emirates Journal of Food and Agriculture 25(7): $501-$ 508.

An, X., Liao, Y., Zhang, J., Dai, L., Zhang, N., Wang, B., Liu, L., \& Peng, D. 2015. Overexpression of rice NAC gene SNAC1 in ramie improves drought and salt tolerance. Plant Growth Regulation 76(2): 211-223.

Ardie, S. W., Khumaida, N., Nur, A., \& Fauziah, N. 2015. Early identification of salt tolerant foxtail millet (Setaria italica L. Beauv). Procedia Food Science 3: 303-312.

Ashraf, M. \& Foolad, M. R. 2013. Crop breeding for salt tolerance in the era of molecular markers and marker-assisted selection. Plant Breeding 132(1): 10-20.

Bennetzen, J. L., Schmutz, J., Wang, H., Percifield, R., Hawkins, J., Pontaroli, A. C., Estep, M., Feng, L., Vaughn, J. N., Grimwood, J., Jenkins, J., Barry, K., Lindquist, E., Hellsten, U., Deshpande, S., Wang, X., Wu, X., Mitros, T., Triplett, J., Yang, X., Ye, C. Y., Mauro-Herrera, M., Wang, L., Li, P., Sharma, M., Sharma, R., Ronald, P.C., Panaud, O., Kellogg, E.A., Brutnell, T. P., Doust, A. N., Tuskan, G. A., Rokhsar, D., \& Devos, K. M. 2012. Reference genome sequence of the model plant Setaria. Nature Biotechnology 30(6): 555-561.

Chen, Q., Wang, Q., Xiong, L., \& Lou, Z. 2011. A structural view of the conserved domain of rice stress-responsive NAC1. Protein and Cell 2(1): 55-63.

Crooks, G. E., Hon, G., Chandonia, J. M., \& Brenner, S. E. 2004. WebLogo: a sequence logo generator. Genome Research 14(6): 1188-1190.

Dhindsa, R. S., Dhindsa, P. P., \& Thorpe, T. A. 1981. Leaf senescence: Correlated with increased levels membrane permeability and lipid peroxidation and decreased levels of SOD and CAT. Journal of Experimental Botany 32: 93-101.

Fang, Y., You, J., Xie, K., Xie, W., \& Xiong, L. 2008. Systematic sequence analysis and identification of tissue-specific or stress-responsive genes of NAC transcription factor family in rice. Molecular Genetics and Genomics 280(6): 547-563.

Hirayama, T. \& Shinozaki, K. 2010. Research on plant abiotic stress responses in the post-genome era: past, present and future. Plant Journal 61(6): 1041-1052.

Hong, Y., Zhang, H., Huang, L., Li, D., \& Song, F. 2016. 
Overexpression of a stress-responsive NAC transcription factor gene ONACO22 improves drought and salt tolerance in rice. Frontiers in Plant Science 7: 4.

Hu, H., Dai, M., Yao, J., Xiao, B., Li, X., Zhang, Q., \& Xiong, L. 2006. Overexpressing a NAM, ATAF, and CUC (NAC) transcription factor enhances drought resistance and salt tolerance in rice. Proceedings of the National Academy of Sciences of the United States of America 103(35): 12987-12992.

Hu, H., You, J., Fang, Y., Zhu, X., Qi, Z., \& Xiong, L. 2008. Characterization of transcription factor gene SNAC2 conferring cold and salt tolerance in rice. Plant Molecular Biology 67(1-2): 169-181.

Huang, Q., Wang, Y., Li, B., Chang, J., Chen, M., Li, K., Yang, G., \& He, G. 2015. TaNAC29, a NAC transcription factor from wheat, enhances salt and drought tolerance in transgenic Arabidopsis. BMC Plant Biology 15: 268.

Islam, M. S., Akhter, M. M., Sabagh, A. E., Liu, L. Y., Nguyen, N. T., Ueda, A., Masaoka, Y., \& Saneoka, H. 2011. Comparative studies on growth and physiological responses to saline and alkaline stresses of Foxtail millet (Setaria italica L.) and Proso millet (Panicum miliaceum L.). Australian Journal of Crop Science 5(10): 1269-1277.

Jensen, M. K., Kjaersgaard, T., Nielsen, M. M., Galberg, P., Petersen, K., O'Shea, C., \& Skriver, K. 2010. The Arabidopsis thaliana NAC transcription factor family: structure-function relationships and determinants of ANAC019 stress signalling. Biochemical Journal 426(2): 183189.

Kafi, M., Zamani, G. S., \& Ghoraishi, G. 2009. Relative salt tolerance of south Khorasan millets. DESERT 14: 63-70.

Karyudi, \& Fletcher, R. J. 2003. Osmoregulation in birdseed millet under conditions of water stress II. Variation in F3 lines of Setaria italica and its relationship to plant morphology and yield. Euphytica 132(2): 191-197.

Kosugi, S., Hasebe, M., Matsumura, N., Takashima, H., MiyamotoSato, E., Tomita, M., \& Yanagawa, H. 2009. Six classes of nuclear localization signals specific to different binding grooves of importin $\alpha$. Journal of Biological Chemistry 284(1): 478-485.

Kumar, S., Stecher, G., \& Tamura, K. 2016. MEGA7: Molecular Evolutionary Genetics Analysis Version 7.0 for bigger datasets. Molecular Biology and Evolution 33(7): 1870-1874.

Lapuimakuni, S., Khumaida, N., \& Ardie, S. W. 2018. Evaluation of drought tolerance indices for genotype selection of foxtail millet (Setaria italica). Tropical Drylands 2(2): 37-40.

Larkin, M. A., Blackshields, G., Brown, N. P., Chenna, R., McGettigan, P. A., McWilliam, H., Valentin, F., Wallace, I. M., Wilm, A., Lopez, R., Thompson, J. D., Gibson, T. J., \& Higgins, D. G. 2007. Clustal W and Clustal X version 2.0. Bioinformatics 23(21): 2947-2948.

Lata, C., Sahu, P. P., \& Prasad, M. 2010. Comparative transcriptome analysis of differentially expressed genes in foxtail millet (Setaria italica L.) during dehydration stress. Biochemical and Biophysical Research Communications 393(4): 720727.

Murray, M. G. \& Thompson, W. F. 1980. Rapid isolation of high molecular weight DNA. Nucleic Acids Research 8: 4321-4325.

Liu, G., Li, X., Jin, S., Liu, X., Zhu, L., Nie, Y., \& Zhang, X. 2014. Overexpression of rice NAC gene SNAC1 improves drought and salt tolerance by enhancing root development and reducing transpiration rate in transgenic cotton. PLoS One 9(1): e86895.

Nakashima, K., Takasaki, H., Mizoi, J., Shinozaki, K., \& Yamaguchi-Shinozaki, K. 2012. NAC transcription factors in plant abiotic stress responses. Biocbimica et Biophysica Acta 1819(2): 97-103.

Olsen, A. N., Ernst, H. A., Leggio, L. L., \& Skriver, K. 2005. NAC transcription factors, structurally distinct, functionally diverse. Trends in Plant Science 10(2): 79-86.

Panaud, O. 2006. Foxtail millet. In: Genome mapping and molecular breeding in plants: cereals and millet. Ed. Kole, C. pp. 325-332. Berlin: Springer-Verlag.

Puranik, S., Bahadur, R. P., Srivastava, P. S., \& Prasad, M. 2011. Molecular cloning and characterization of a membrane associated NAC family gene, SiNAC from foxtail millet [Setaria italica (L.) P. Beauv.]. Molecular Biotechnology 49(2): 138-150.

Puranik, S., Sahu, P. P., Srivastava, P. S., \& Prasad, M. 2012. NAC proteins: regulation and role in stress tolerance. Trends in Plant Science 17(6): 369-381.

Puranik, S., Sahu, P. P., Mandal, S. N., Suresh, V., Parida, S. K., \& Prasad, M. 2013. Comprehensive genome-wide survey, genomic constitution and expression profiling of the NAC transcription factor family in foxtail millet (Setaria italica L. Beauv). PLoS One 8(5): e64594.

Sakuma, Y., Matuyama, K., Osakabe, Y., Qin, F., Seki, M., Shinozaki, K., \& Yamaguchi-Shinozaki, K. 2006. Functional analysis of an Arabidopsis transcription factor DREB2A, involved in drought-responsive gene expression. The Plant Cell 18(5): 1292-1309.

Shinde, H., Dudhate, A., Tsugama, D., Gupta, S. K., Liu, S., \& Takano, T. 2019. Pearl millet stress-responsive NAC transcription factor PgNAC21 enhances salinity stress tolerance in Arabidopsis. Plant Physiology and Biochemistry 135: 546-553.

Sreenivasulu, N., Grimm, B., Wobus, U., \& Weschke, W. 2001. Differential response of antioxidant compounds to salinity stress in salt-tolerant and salt-sensitive seedlings of foxtail millet (Setaria italica). Physiologia Plantarum 109: 435-442.

Turan, S., Cornish, K., \& Kumar, S. 2012. Salinity tolerance in plants: Breeding and genetic engineering. Australian Journal of Crop Science 6(9): 1337-1348.

Widyawan, M. H, Khumaida, N., Kitashiba, H., Nishio, T., \& Ardie, S.W. 2018. Optimization of dot-blot SNP analysis for the detection of drought or salinity stress associated marker in foxtail millet (Setaria italica L.). SABRAO Journal of Breeding and Genetics 50(1): 72-84.

Wu, A., Allu, A. D., Garapati, P., Siddiqui, H., Dortay, H., Zanor, M., Asensi-Fabado, M. A., Munné-Bosch, S., Antonio, C., Tohge, T., Fernie, A. R., Kaufmann, K., Xue, G., MuellerRoeber, B., \& Balazadeh, S. 2012. JUNGBRUNNEN1, a reactive oxygen species-responsive NAC transcription factor, regulates longevity in Arabidopsis. The Plant Cell 24(2): 482-506.

Wu, Y., Deng, Z., Lai, J., Zhang, Y., Yang, C., Yin, B. Zhao, Q., Zhang, L., Li, Y., Yang, C., \& Xie, Q. 2009. Dual function of Arabidopsis ATAF1 in abiotic and biotic stress responses. Cell Research 19(11): 1279-1290.

Yang, X., Wan, Z., Perry, L., Lu, H., Wang, Q., Zhao, C., Li, J., Xie, F., Yu, J., Cui, T., Wang, T., Li, M., \& Ge, Q. 2012. Early millet uses in northern China. Proceedings of the National Academy of Sciences of the United States of America 109(10): 37263730.

You, J., Zhang, L., Song, B., Qi, X., \& Chan, Z. 2015. Systematic analysis and identification of stress-responsive genes of the NAC gene family in Brachypodium distachyon. PLoS One 10(3): e0122027. 